\title{
Desktop Micro Forming System for Micro Pattern on the Metal Substrate
}

\author{
Hye-Jin Lee ${ }^{1}$, Jung-Han Song ${ }^{1}$, Sol-Kil Oh ${ }^{1}$, Kyoung-Tae Kim ${ }^{1}$, Nak-Kyu Lee ${ }^{1}$, \\ Geun-An Lee ${ }^{1}$, Hyoung-Wook Lee ${ }^{2}$, and Andy Chu ${ }^{3}$ \\ ${ }^{1}$ Manufacturing Convergence R\&D Department, \\ Korea Institute of Industrial Technology, Korea \\ ${ }^{2}$ Dept. of Energy System Engineering, Chungju National University, Korea \\ ${ }^{3}$ Space Solution Co., Ltd. Seoul, Korea \\ \{naltl, jhsong, solkil,ktkim, nklee, galee\}@kitech.re.kr, \\ hwlee@cjnu.ac.kr, crimsonlespacesolution.kr
}

\begin{abstract}
In this Research, the desktop micro forming manufacturing system has been developed. A micro forming system has been achieved in Japan and its developed micro press is limited to single forming process. To coincide with the purpose to be more practical, research and development is necessary about the press which the multi forming process is possible. Micro patterned metal components are used in so many precision engineering fields. This micro pattern plays an important part in the functional movement of precision module. This micro pattern on the metal component can be made by EDM(Electro Discharge Machining). But this EDM method has low productivity because EDM tools can be worn easily. If another manufacturing process is developed with high productivity, industries can product the competitive goods. So we research on the forming process and system to make micro functional pattern on the metal component.
\end{abstract}

Keywords: Micro Metal Forming, Forming Manufacturing System, Micro Thin Foil Valve, Multi Processing.

\section{Introduction}

The existing forming press uses a hydraulic actuator and high powered mechanical actuator (Fig.1-(a)), therefore occupying a large space because of its size. This type of system is inefficient for manufacturing micro size and precision products.

As forming components are small in size, forming equipment must also be small in size because the forming die and load must be small. The micro manufacturing press system is an ultra precision forming equipment the size of several micros to millimeters and precision of sub-micro to micrometer. This system can be applied to a micro factory system module that manufactures micro components using micro thin foil and bulk material. This micro forming manufacturing system (Fig.1-(b)) has the advantage of minimization in manipulating distance and working space. As equipment and tools become smaller in size, minute inertia force and high natural frequency can be obtained. Therefore, high precision forming performance can be obtained. This allows the factory to quickly provide the customer with goods because the manufacturing system and process are reduced. To construct a micro manufacturing system, many technologies are necessary such as high stiffness frame, high precision actuating part, structural analysis, high precision tools and system control. 


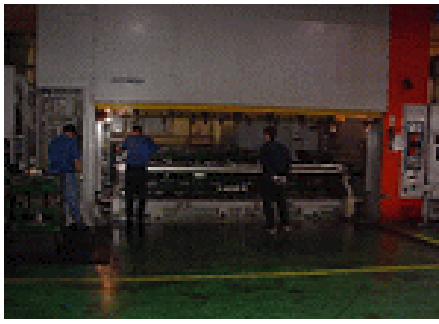

(a)

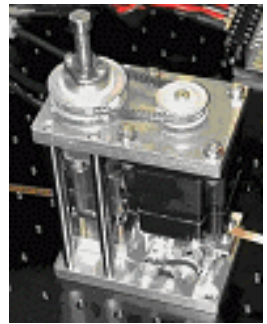

(b)

Fig. 1. (a) Existing forming press and (b) Micro forming press

Most of the research about microscopic sized forming is underway concentrating in forming on the polymer substrate. But the research on the micro forming equipment miniaturization and forming technology on the metal substrate are insufficient than the microscopic sized forming technology on the polymer substrate.

This research is about research on the modified desktop micro forming system to manufacture the micro pattern on the metal substrate and maximize the efficiency of micro forming process. This desktop micro forming system is developed in collaboration with KITECH (Korea Institute of Industrial Technology) and Space Solution Inc. The modified system is consists of gear type actuating module and micro compressive forming die-set. The forming results of micro herringbone pattern are described to verify the performance of developed system.

\section{Related Research about Micro Manufacturing System}

The micro machine project was the initial step in the micro manufacturing system. This project has become the leading research in micro manufacturing with national support by MITI (Economy, Trade and Industry Ministry). MITI has infused a total of two-hundred million dollars into this project over the past 10 years since 1991. In this project, AIST (National Institute of Advanced Industrial Science and Technology) developed a micro milling machine, micro lathe, micro press, component transport section, and assembly section on a flat table the size of $500 \mathrm{~mm} \times 700 \mathrm{~mm}$. AIST manufactured a miniature bearing module using this micro factory system. A picture of the micro press system is shown in Fig. $1 \mathrm{~b}$ and the size of this micro press system is $111 \mathrm{~mm} \times 66 \mathrm{~mm} \times 170 \mathrm{~mm}$ (length $\mathrm{x}$ width $\mathrm{x}$ height). This system is driven with a $100 \mathrm{~W}$ AC serve motor and a maximum load capacity of $3 \mathrm{kN}$. AIST manufactured a $\Phi 1 \mathrm{~mm}$ miniature bearing module cover part in a bending process using the micro press system. However, research has been restricted to the bending process and its practical efficiency is low.

TIT (Tokyo Institute of Technology) designed the micro punching press system as shown in Fig.2. A micro pump using a piezo is used for an actuator of the micro punching press system. TIT carried out a $300 \mu \mathrm{m}$ hole punching process on the $10 \mu \mathrm{m}$ thickness aluminum foil. The punching force is $1.85 \mathrm{kN}$ in this process. The pictures of the punch and the fabricated micro hole are shown in Fig.3. 


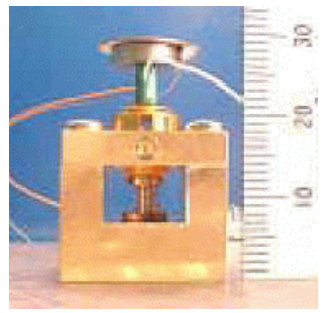

Fig. 2. Micro Press of Tokyo Institute of Technology
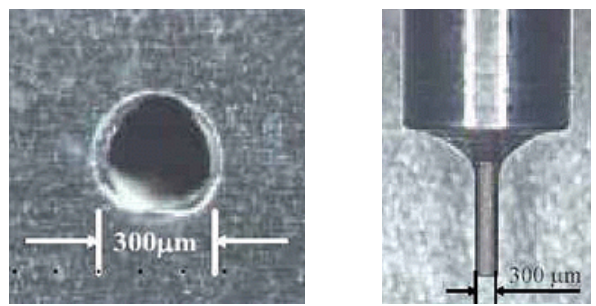

Fig. 3. Picture of Micro Punch and Fabricated Micro Hole

\section{Development of Desktop Micro Forming System and Compressive Forming Die-Set}

The size and load capacity of the desktop micro forming system must have a desktop size and to under 5Tonf as result that achieve investigation and research about optimal size and load capacity that equipment of commercialization concept must have as progressing research for press equipment's miniaturization to form micro component [1-2]. Forming system that has a specification more than this is classified into that it is suitable to product macro sized components that have milli size than micro. In this research, the desktop micro forming system planed to have target specification in Table 1. Structure and design optimization are achieved according to the target specification in Table 1 and can be obtained the final 3D CAD model such as Fig. 4. The desktop micro forming system is designed with precision actuating guide and flexible forming performance. The size of system is $260 \times 340 \times 655(\mathrm{~W} \times \mathrm{D} \times \mathrm{H}, \mathrm{mm})$. A precision guide module consists of AC servo geared motor, gear module, precision ball

Table 1. Specification of Modified Desktop Micro Forming System

\begin{tabular}{cc}
\hline Specification & Description \\
\hline Size & $260 \times 340 \times 655(\mathrm{~W} \times \mathrm{D} \times \mathrm{H}, \mathrm{mm})$ \\
Forming Capacity & $4.0 \mathrm{Tonf}$ \\
Max. Speed & $400 \mathrm{~mm} / \mathrm{min}$ \\
Stroke Resolution & $0.1 \mu \mathrm{m}$ \\
Actuating Type & AC Servo Geared Type \\
\hline
\end{tabular}



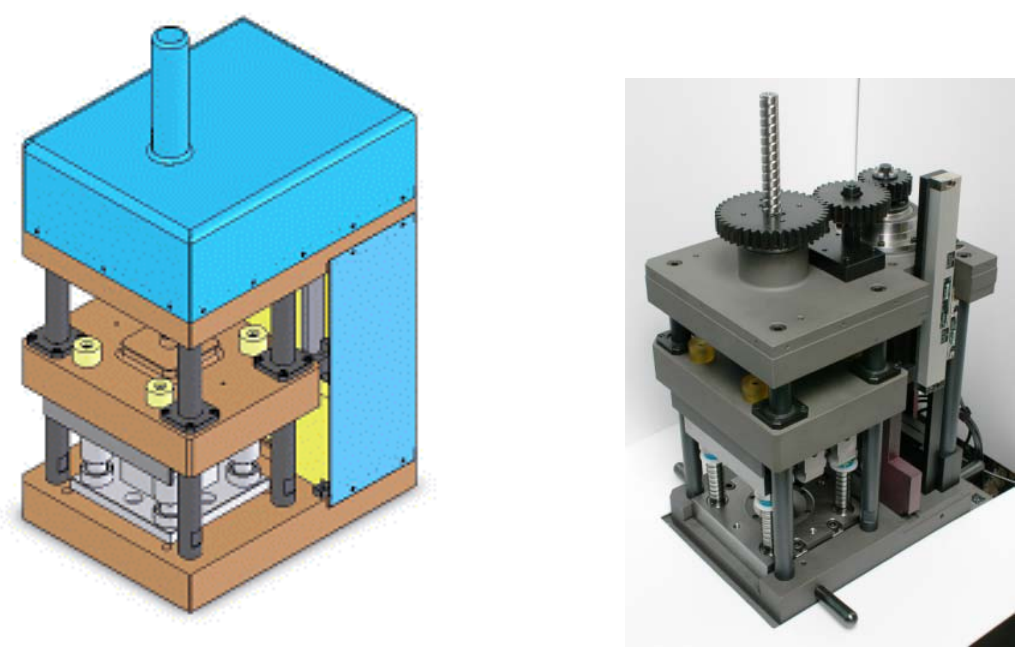

Fig. 4. CAD model of desktop forming system Fig. 5. Manufactured desktop forming system

screw and guide 4-post module. The picture of manufactured desktop micro forming system with this optimal design result is displayed in Fig. 5.

This manufactured desktop micro forming system is designed and manufactured could be suitable to various micro components forming process. This system use a exclusive die set that can form the component between base part and cross head part of system, so that can apply this system to flexible micro forming application.

This desktop micro forming system is operated using AC geared servo motor and high precision ball screw, and applied a geared module as additional so that can regulate a forming speed and increase the forming load capacity. The gear module and AC servo motor structure's pictures applied to this system are shown in Fig. 6.

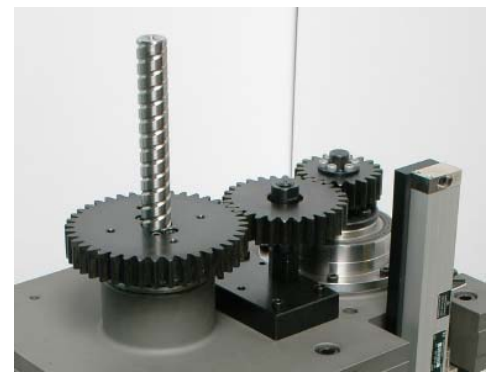

(a) Gear driven module

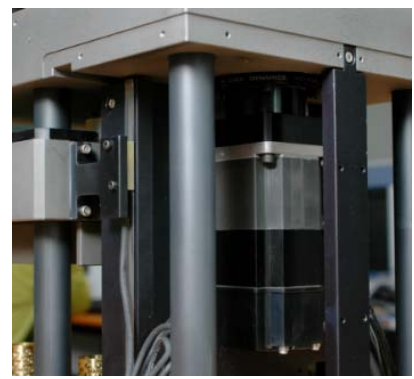

(b) AC servo motor is attached to gear driven structure

Fig. 6. Gear module and AC servo motor structures to make a variable forming speed 
The desktop micro forming system and die set to manufacture a micro patterned component must have a micron size accuracy, so the precision displacement control fewer than sub-micro must be needed to prevent a damage by an over load of die set and system. The linear displacement sensor that have a resolution of $0.1 \mu \mathrm{m}$ is applied to the system to solve these precision displacement control problem. And a precision displacement feedback control fewer than sub-micro can be achieved using this sensor. The linear displacement sensor's picture that have a resolution of $0.1 \mu \mathrm{m}$ is shown in Fig. 7.

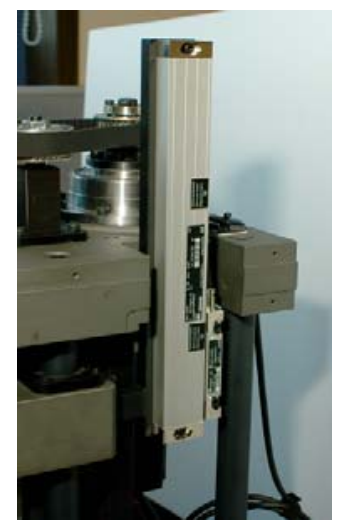

Fig. 7. The linear displacement sensor that have a resolution of $0.1 \mu \mathrm{m}$

\section{Manufacturing of Compressive Die Set for the Micro Herringbone Pattern}

This research established by research target that achieve the micro herringbone pattern on the metal substrate. This micro herringbone pattern is used to generate the

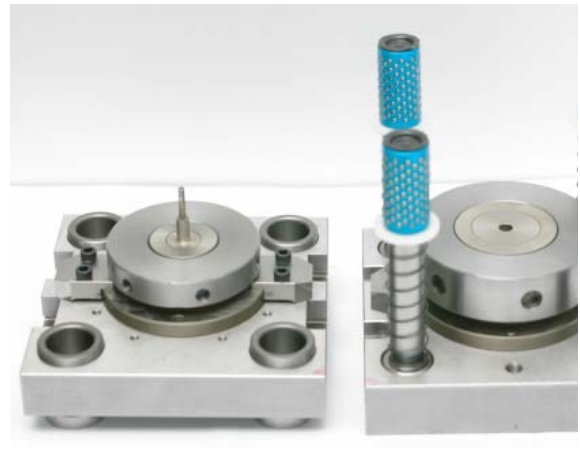

(a) Manufactured die set

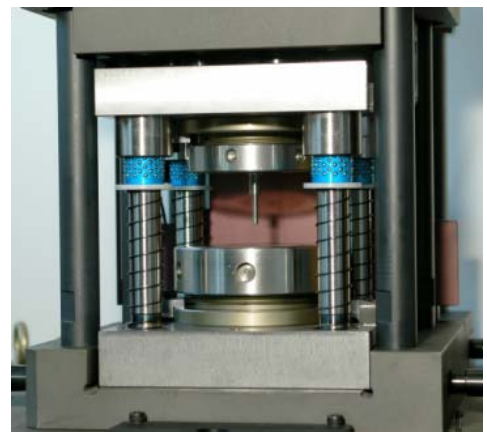

(b) Equipped die set to the micro forming system

Fig. 8. Manufactured die set of a herringbone pattern forming and equipped die set module to this micro forming system 
hydraulic dynamic pressure in so many application fields. The pictures of a manufactured die set of a herringbone pattern forming and equipped to this micro forming system are shown in Fig. 8.

\section{Forming Results of Micro Herringbone Pattern on the Metal Substrate}

In this research, the micro herringbone pattern is formed on the metal substrate (Stainless sintering substrate). The forming load of the micro herringbone pattern forming on the SUS sintering substrate is about $21 \mathrm{kN}$. The precision machined mold is shown in Fig. 9 and forming results are shown in Fig. 10. The micro herringbone pattern is formed with about 10 20 microns height and good quality shape. Fig. 11 indicates that we can acquire the micro spiral pattern with the depth of $14 \mu \mathrm{m}$ above the forming load of 1300kgf, which is acceptable in the application of actual FDB in hard disk drive.
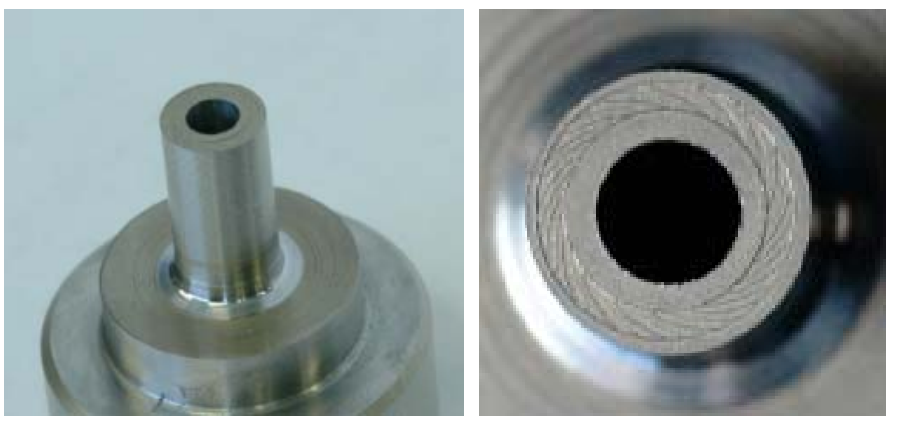

Fig. 9. Manufactured mold for forming the herringbone pattern on the metal substrate

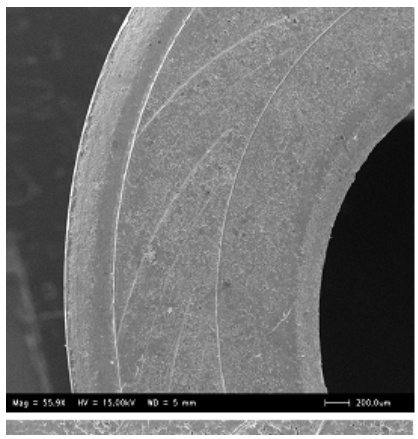

Fig. 10. Top-view SEM of FDB (forming load:1,400Kgf) 

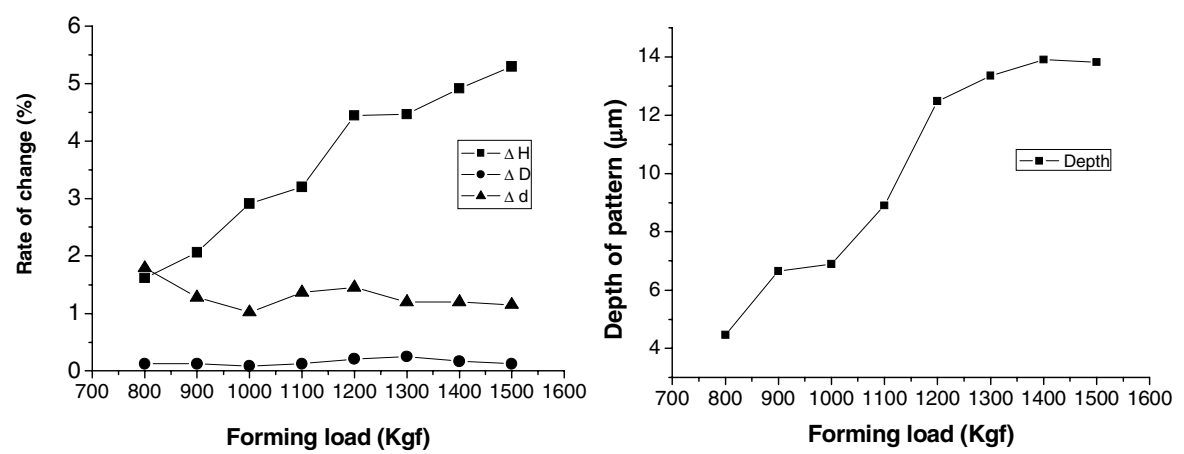

Fig. 11. Deformed shape of the herringbone pattern with various forming loads

\section{Conclusion}

This paper deals with a novel technique for the fabrication of spiral grooves in a dynamic thrust bearing. The main scheme proposed in this paper is to fabricate the microgrooves using desktop forming system. At first, a desktop press system was newly designed as shown in Fig. 1. The micro press system and die set to fabricate herringbone patterns should have a micron size accuracy, so the detailed displacement control fewer than sub-micro must be needed to prevent a damage by an overload of the die set and system. The linear displacement sensor that has a resolution of $0.1 \mathrm{um}$ is adopted to the system to guarantee the precise displacement control. Using this sensor, precise displacement feedback control fewer than sub-micro can be achieved. After that, die sets were also designed with the aid of finite element analysis. Tool dimension and shape of die sets shown in Fig. 2 were determined from the FE results. Finally, micro forming tests were conducted with the developed desktop system and die sets. The testing material is sinter-forged cupper used in the actual FDB. In order to evaluate the formability and forming accuracy, SEM image of fabricated herringbone patterns were observed after the test. Experimental results demonstrate that herringbone grooves in FDB can be fabricated micro forming method using desktop press system to keep the product manufacturing time and costs low.

\section{Acknowledgement}

This work has been financially supported by Ministry of Knowledge Economy in Korea through Strategic Technology Development Project (Development of Micro Functional Precision Components Manufacturing Technology). The authors are also grateful to the colleagues for their essential contribution to this work.

\section{References}

1. Lee, H.-J., Lee, N.-K., Choi, S.: Development of Miniaturized Micro Metal Forming Manufacturing System. Materials Science Forum 544-545, 223-226 (2007) 
2. Lee, H.-J., Lee, N.-K., Lee, S.-M., Lee, G.-A., Kim, S.-S.: Development of Micro Metal Forming Manufacturing System. Materials Science Forum 505-507, 19-24 (2006)

3. Joo, B.Y., Oh, S.I., Son, Y.K.: Forming of Micro Channels with Ultra Thin Metal Foils. CIRP Annals - Manufacturing Technology 53(1), 243-246 (2004)

4. Groche, P., Schneider, R.: Method for the Optimization of Forming Presses for the Manufacturing of Micro Parts. CIRP Annals - Manufacturing Technology 53(1), 281-284 (2004)

5. Tourki, Z., Zeghloul, A., Ferron, G.: Sheet metal forming simulations using a new model for orthotropic plasticity. Computational Materials Science 5, 255-262 (1996) 